\title{
JOANA D'ARC EM LUTA PELA DIGNIDADE: UMA PRÁTICA \\ EM DESENVOLVIMENTO COMUNITÁRIO
}

\author{
JOANA D'ARC FIGHTING FOR \\ DIGNITY: A PRACTICE IN \\ COMMUNITY DEVELOPMENT
}

\section{RESUMO}

Discute-se neste artigo uma prática de desenvolvimento comunitário realizada ao longo de cinco anos (2005-2010) na Vila Joana d'Arc, periferia de Porto Alegre/RS. Esta iniciativa, intitulada Projeto Joana d'Arc em Luta pela Dignidade, esteve vinculada ao setor de Desenvolvimento Social da Pontifícia Universidade Católica do Rio Grande do Sul e contou com o patrocínio do Programa Desenvolvimento \& Cidadania, da Petrobras. O projeto teve como objetivo melhorar a qualidade de vida dos moradores através da implementação de um empreendimento coletivo, visando a geração de trabalho e renda para um grupo de mulheres. Aliado a isso, buscou problematizar as dificuldades da vivência e da articulação do grupo para o desenvolvimento de um trabalho calcado na coletividade. A metodologia utilizada foi essencialmente participativa e dialógica, ou seja, foi através da constituição de vínculos significativos, da amorosidade entre educadores e educandos, que a militância cotidiana ganhou espaço para incentivar a autonomia e o protagonismo da comunidade no processo de transformação social. Após cinco anos de ação comunitária, os principais resultados foram: formação de 37 mulheres na área de padaria e confeitaria; construção de uma sede para o empreendimento coletivo e outro espaço complementar para as atividades comunitárias; aquisição de maquinário específico; formação de 19 mulheres para trabalhar com crianças na função de Educador Assistente; implementação de um conjunto de ações interdisciplinares que contribuíram para a melhoria de diferentes aspectos da vida comunitária

Palavras-chave: Educação Popular, Economia Solidária, Dialogicidade, Militância, Transformação Social.

\section{ABSTRACT}

This paper discusses a community development practice conducted for five years (2005-2010) in the Joana d'Arc community, in the poor outskirts of Porto Alegre/RS. This initiative, called Joana d'Arc fighting for Dignity Project, was linked to the Social Development sector of the Pontifical Catholic University of Rio Grande do Sul was sponsored by the Development and Citizenship Program, Petrobras. The project

\footnotetext{
* Professora do Centro Universitário La Salle (UNILASALLE), RS - Brasil. E-mail: aline.accorssi@unilasalle.edu.br
}

** Psicóloga da Associação de Moradores da Vila Tijuca, RS - Brasil. E-mail: crismaranzana@yahoo.com.br 
aimed at the improvement of the quality of life of residents through the implementation of a collective enterprise, which offers employment and income generation for a group of women. In addition, it sought a way to problematize the living difficulties and the articulation of the group for the development of a work grounded on collectivity. The methodology was essentially participatory and dialogic. Thus, it was through the establishment of meaningful links, such as caring between educators and students, that daily militancy gained space to encourage autonomy as well as the central role of the community in the process of social transformation. After five years of community actions, the main results were: 37 women trained in bakery and pastry skills; the construction of a place for the collective enterprise as well as an additional space for community activities; acquisition of specific machinery; 19 women trained to work with children as Educator Assistants; and the implementation of a set of interdisciplinary actions that contributed to the improvement of various aspects of community life.

Keywords: Popular Education; Solidarity Economy; Dialogicity; Militancy; Social Transformation.

\section{Notas introdutórias}

Vivemos em um tempo paradoxal de grandes revoluçóes tecnológicas, comunicacionais, da genética e da biotecnologia; um período de grandes achados que, segundo as promessas da modernidade, nos libertariam de presas do passado. A narrativa de legitimação desse tempo foi a busca da emancipação humana, que viria a partir da liberdade, da igualdade, da solidariedade e da paz, tudo isso como consequência "natural" do progresso material, com a melhoria significativa da qualidade de vida da sociedade.

O paradoxo, no entanto, está no fato de que, hoje mais do que nunca, parece haver possibilidades técnicas para cumprirmos os ideais da modernidade, mas estamos cada vez mais longe de os conquistar, uma vez que nosso tempo está emaranhado por problemas modernos, para os quais parece não haver soluçóes modernas. Logo, o que está em jogo, segundo Santos (2002), é a reinvenção da emancipação social através de uma globalização alternativa.

No presente trabalho, portanto, partimos do pressuposto de que a realidade náo se reduz ao que existe, ao que está dado como imutável e natural (SANTOS, 2000), mas, ao contrário, ela sempre deve ser pensada enquanto um campo de possibilidades para a emergência de novas formas de ser e fazer $o$ e no mundo. O papel de uma teoria crítica, nesse caso, é o de ampliar as possibilidades através da experimentação e da reflexão acerca de alternativas que conduzam a construção de sociedades mais justas (SANTOS, 2002). Pensamos ser relevante refletir e problematizar as possíveis saídas encontradas pela sociedade aos processos de empobrecimento e exclusão social que a populaçáo brasileira historicamente tem vivenciado e produzido.

Assim, nosso objetivo com este artigo é apresentar e discutir, à luz da psicologia social crítica, uma prática de desenvolvimento comunitário realizada entre outubro de 2005 e dezembro de 2010 na Vila Joana d'Arc, periferia de Porto Alegre/RS, por uma equipe de profissionais e alunos de diferentes cursos e campos de conhecimento. Essa iniciativa, intitulada Projeto Joana d'Arc em Luta pela Dignidade, esteve inserida institucionalmente no Setor de Desenvolvimento Social da Pontifícia Universidade Católica do Rio Grande do Sul (PUCRS) e realizada em parceira com o Programa Desenvolvimento \& Cidadania da Petrobras. O projeto teve como foco prioritário de ação melhorar a qualidade de vida dos moradores através da construção e implementação de um empreendimento coletivo (padaria e confeitaria), visando a geração de trabalho e renda para um grupo de mulheres da comunidade.

Aliado a isto, buscou-se discutir e problematizar as dificuldades da vivência e da articulaçáo do grupo para o desenvolvimento de um trabalho calcado na coletividade, ou seja, nos valores e princípios 
da Economia Solidária (SINGER, 2002; SANTOS, 2002). Uma vez que a comunidade náo dispunha de instituiçôes educativas e de espaços coletivos de lazer voltadas às crianças e que, por conta disto, inúmeras dificuldades do cotidiano familiar inviabilizavam a participaçáo feminina das açóes comunitárias, buscamos criar um espaço lúdico-educativo direcionado prioritariamente aos filhos e filhas das trabalhadoras, bem como, mobilizar a rede pública para a implementação de açôes permanentes na região.

A metodologia que utilizamos ao longo do processo de desenvolvimento do projeto foi essencialmente participativa e fundamentada na perspectiva da educação dialógica (FREIRE, 1987). Em outras palavras, podemos afirmar que foi através da constituiçáo de vínculos fortalecidos e da amorosidade entre educadores e educandos que a militância (MORETTI, 2008) cotidiana ganhou espaço para incentivar a autonomia e o protagonismo da comunidade no processo de transformaçáo social.

Neste artigo, portanto, buscamos delinear o acúmulo de mais de cinco anos de experiência em desenvolvimento comunitário baseado na educação popular. Para isso, em um primeiro momento, tratamos dos aspectos teóricos que fundamentam nossa ação e compreensão da realidade; em seguida, trilhamos a nossa práxis marcando alguns momentos ou experiências relevantes para possibilitar a compreensão do processo como um todo. Por fim, fazemos algumas "reflexões e questôes para não finalizar", em outras palavras, discutimos os elementos centrais para a sustentabilidade da iniciativa, bem como as limitaçôes da nossa própria ação.

\section{Fundamentos teóricos da experiência}

Se por um lado "sem prática não há conhecimento" (Freire e Horton, 2002, p. 112), por outro compreendemos que o conhecimento se nutre e se fortalece com as teorias, as quais, quando tomadas como criação e ação humana sendo, portanto, históricas e passíveis de contradiçôes, podem nos fornecer lentes de análise do campo social que estudamos, onde agimos. Tais lentes focam em certos aspectos e, ao mesmo tempo, desfocam em outros, pois a incompletude, característica ontológica, também está presente nas produçôes humanas.

Conscientes das limitaçóes e da não neutralidade das escolhas, tomamos como teoria de base para fazer a leitura de mundo, bem como para sustentar nossa prática, a Psicologia Social Crítica, que se difere pelo seu propósito fundamental, que é a busca pelo esclarecimento e pela emancipação. Ela "toma partido e não vê como se possa deixar de tomar partido" (GUARESCHI, 1993, p. 43) e, devido a isso, rompe com os pressupostos da ciência moderna, em que se prezava a neutralidade e objetividade da pesquisa. É sempre reflexiva, autorreferente, parte do 'objeto' que descreve e analisa; ela é crítica, primeiramente, dela mesma, rejeitando a absolutizaçáo dos fatos da sociedade e das pessoas, pois considera que um fenômeno social somente ocorre sob certas condiçôes de mundo, condiçóes históricas.

Para essa teoria, nada seria natural, nem o ser humano, que é aqui entendido como um ser de relaçôes (GUARESCHI, 2004), que se cria e se forma a partir das interpelaçóes provocadas pelo outro. Contudo, ele é muito mais do que a soma das relaçôes, aliás, pensamos que seria impossível ser essa somatória, pois senão o ser humano seria uma espécie de tábua rasa sobre a qual as outras pessoas imprimiriam suas marcas à medida 
em que fossem se relacionando. Ao contrário, pensamos que a cada interpelaçáo do outro no sujeito, há um processo de significação que o transforma para além do que ele e o outro eram. Contudo, essa noção de ser humano enquanto um ser de relação também precisa estar contextualizada em certo momento histórico-social, por isso em nosso caso buscamos as discussóes em torno do conceito de contemporaneidade para compreender qual ser de relação é pertencente a esse tempo histórico.

Em linhas gerais, a contemporaneidade, conforme Lipovetsky (1993), é marcada por um individualismo puro, uma desafeiçáo generalizada que ostensivamente se afirma no social. É um período de despolitização e dessindicalização em que a esperança revolucionária e a contestação ao sistema econômico, político e social quase que desapareceram, uma vez que raras sáo as causas coletivas que se mobilizam, pois somente a esfera privada parece ter sido fortificada. Zela-se, por exemplo, pela saúde, busca-se perder os 'complexos', vive-se sem grandes ideais e sem a esperança de um fim transcendente. "Sob muitos aspectos, esta fórmula traduz o novo espírito do tempo: o fim do homo politicus e o advento do homo psychologicus, à espreita do seu ser e do seu bem-estar" (LIPOVETSKY, 1993, p. 49).

Nesse contexto, há uma perda do sentido de continuidade histórica: vive-se no presente, apenas no presente, e não em função do passado e do futuro. Assim, o sentido histórico sofre a mesma deserçấo que os valores e as instituiçôes sociais: vivemos para nós mesmos, sem nos preocuparmos com as nossas tradiçóes ou com a nossa posteridade.

Um dos grandes riscos desse processo de ruptura com passado é a naturalização dos fatos e acontecimentos e, como consequência, a apatia frente a situação do mundo prova disso é o modo como tendemos a tratar a economia e o próprio sistema capitalista. De modo geral, aceita-se o fato de que a economia pode e deve ser competitiva, afinal nos traz benefícios no cotidiano: preços mais baixos devido à concorrência; os que melhor atendem aos consumidores são os ganhadores, enquanto os que não conseguem são categorizados como os perdedores ou os excluídos.

O neoliberalismo (SOARES, 2002), enquanto um novo modelo de acumulação implementado na América Latina a partir dos anos de 1970, reafirma esses valores e inclui, entre outros aspectos, a culpabilização do indivíduo pelo não sucesso no mundo, criando assim uma sociedade fragmentada e polarizada entre ganhadores e perdedores (SINGER, 2002). Os primeiros acumulam capital e os segundos acumulam dívidas, além de serem despedidos ou ficarem desempregados até se tornarem os "inempregáveis". Contudo, essa competiçáo econômica, bem como os valores que a sustentam, tem sido alvo de debate em nossos dias devido às consequências sociais que estáo evidentemente nela implicadas.

A Economia Solidária, por exemplo, é um campo de ação/reflexão fundamental para pensar em saídas alternativas ao modelo hegemônico. Ela possui acepçóes diversas, mas todas giram em torno da ideia de solidariedade em contraste ao individualismo competitivo, conforme vimos acima. $\mathrm{O}$ termo se refere a organizaçóes de trabalhadores, consumidores, etc. que se distinguem por estimularem a solidariedade entre os membros através da autogestão e por praticarem a solidariedade para com a população trabalhadora em geral, com ênfase na ajuda aos mais desfavorecidos (SINGER, 2003). A autogestáo significa a completa igualdade de direitos de todos os membros nas organizaçóes; é um conjunto de práticas sociais que se caracterizam por uma natureza democrática de tomada de decisóes, além de ser um exercício de poder compartilhado, que expressa a existência de relaçóes sociais horizontais. 
Evidentemente que esse campo de ação/reflexão anti-hegemônico não é um processo tranquilo e linear. Aliás, tem-se debatido se é possível consolidar a proposta da Economia Solidária enquanto um modelo de produção alternativo, uma vez que fomos constituídos e estamos inseridos em um outro modelo de desenvolvimento social e econômico. De qualquer modo, se considerarmos que a história é um produto da ação humana, pensamos ser possível e necessário alimentar o sonho de que um novo modelo econômico e social pode ser fomentado. A perspectiva do desenvolvimento local endógeno (ZAPATA, 2002), por exemplo, que busca dinamizar os aspectos produtivos e econômicos, potencializar as dimensôes sociais, culturais, ambientais e político-institucionais de modo integrado e com a inserção de múltiplos atores, pode contribuir de modo significativo para a construção de um mundo mais decente.

Nos próximos itens do artigo abordamos como conduzimos o processo de desenvolvimento de nossa ação/reflexão no Projeto Joana d'Arc em Luta pela Dignidade, realizado de 2005 a 2010 em uma comunidade periférica de Porto Alegre (Vila Joana d'Arc), além de discutir a problemática da transformação social da experiência vivida.

\section{3. "O caminho se faz caminhando"}

Tomamos emprestado o nome do livro de Paulo Freire e Myles Horton (2003) para marcar um aspecto fundamental de nosso agir, uma vez que o percurso por nós trilhado ao longo dos cinco anos foi se abrindo e se delineando no próprio caminhar. Tal caminho se caracterizou por uma multiplicidade de pessoas, logo, de intençóes e de desejos em movimento, conforme veremos a seguir. Dessa forma, é importante frisar que o objetivo do projeto do qual estamos tratando era melhorar a qualidade de vida dos moradores daquela comunidade através da implementação de um empreendimento coletivo restrito às mulheres (padaria e confeitaria), além da criação de um espaço lúdico-educativo para as crianças.

\subsection{Primeira fase}

A inserção da equipe na comunidade ocorreu de forma gradativa e cuidadosa, no qual se fez o uso de entrevistas, conversas informais, visitas domiciliares e participação em festas da comunidade. Nossa principal preocupaçáo era construir vínculos que dessem base para o estabelecimento de relaçóes horizontais ao longo do projeto. Para isso, privilegiamos o exercício da escuta e do respeito ao tempo de cada mulher, do grupo e da comunidade de um modo geral.

A postura inicial das mulheres que ingressaram no projeto caracterizava-se pela adesão passiva às atividades propostas pela equipe: pouco questionamento e, em alguns momentos, vergonha e medo de opinar, de agir e até mesmo de se relacionar. Sentíamos um grande receio por parte delas em se expor no grupo, pois utilizar esse espaço para propor algo, por exemplo, significava responsabilizar-se pelo processo.

Em alguns desses momentos, em especial quando observávamos uma certa insegurança das mulheres em relação à participaçáo e/ou a permanência no projeto, dirigíamo-nos até as suas casas (ou a outros espaços da própria comunidade) para 
estabelecer um diálogo com o intuito de proporcionar um espaço de escuta para o fortalecimento de sua participação. Aos poucos, o vínculo, a amorosidade e o respeito passaram a ser constituidores do nosso trabalho.

Depois do grupo composto e se encontrando regularmente, conflitos interpessoais e outras dificuldades ligadas ao cotidiano das mulheres e suas famílias passaram a emergir e a prejudicar a participaçáo delas nas atividades. Assim, a nossa estratégia de visita domiciliar foi se ampliando e constituindo o que passamos a chamar de acompanhamentos individuais, os quais eram caracterizados por ser um espaço de reflexão e produção de sentido sobre suas vivências. Buscamos trabalhar com o potencial de cada uma e estimular uma rede de apoio entre elas, processo semelhante ao que Freire descreve em relação ao empoderamento (FREIRE; SHOR, 1986; GUARESCHI, 2008).

Tendo em vista a consolidação da padaria/confeitaria, optamos por realizar um curso de qualificaçáo profissional consistente, com uma carga horária expressiva. Escolhemos uma instituiçáo de renome no mercado de trabalho, uma vez que as participantes não tinham experienciado essa funçáo enquanto campo profissional e o recebimento de um diploma seria de grande importância. O curso iniciou com a participação de 40 mulheres, sendo que 37 conseguiram finalizá-lo, recebendo o certificado. Atualmente, parte do grupo de mulheres está inserida no mercado formal de trabalho na área de alimentaçáo, outra parte no mercado informal (produzindo alimentos em casa e revendendo em armazéns e escolas) e outras trabalhando de forma coletiva. Percebemos que a retomada da possibilidade de estudar (qualificaçáo profissional) e trabalhar (padaria e confeitaria) empoderou o grupo e as próprias mulheres na vida cotidiana, gerando impactos na forma como as trabalhadoras agem dentro da comunidade e também no núcleo familiar.

Em nossa avaliação, em relaçáo ao alto índice de aproveitamento do curso de qualificação, a conquista aconteceu devido à metodologia participativa que foi gradualmente sendo construída e também pela possibilidade de ter as necessidades emergenciais supridas - o projeto adotou a disponibilização de uma cesta de reforço alimentar para as famílias participantes do grupo de trabalhadoras.

Uma das formas utilizadas para a construçáo e o fortalecimento da metodologia participativa do projeto foi a idealizaçáo de um colegiado gestor, caracterizado como uma instância de reflexáo e monitoramento das açôes que diziam respeito à forma como o projeto deveria ser conduzido. Vários atores que compunham o projeto, como membros da equipe técnica, representantes da instituição parceira da comunidade e mulheres do grupo de trabalhadoras, compartilharam esse espaço de gerenciamento coletivo. Contudo, após um ano e meio de funcionamento, os modos tão diversos de conduzir o projeto passaram a náo mais se comunicar e conflitos emergiram, acabando por desconstituir o espaço oficializado de participação coletiva. Isso não significou a anulação da participação dos grupos e sujeitos envolvidos, ao contrário, novas formas de comunicação nas redes comunitárias passaram a existir, provocando tensionamentos, onde antes havia aceitação.

Com o processo de autonomia se constituindo, as participantes passaram a se interessar pela forma como a verba do projeto estava sendo investida. Esse momento foi crucial, pois passamos a discutir com elas como definir os investimentos materiais, ou seja, o que e onde comprar aquilo que estava previsto nas rubricas. As trabalhadoras tiveram acesso ao orçamento completo, o que enriqueceu a participaçáo nos momentos de tomada de decisão e contribuiu para o fomento da autogestáo e empoderamento. 
Percebemos, ao longo do tempo, uma série de mudanças constituídas a partir da metodologia utilizada. Houve uma significativa transformação na postura das mulheres em relação ao papel da equipe: do assistencialismo ao questionamento, de uma postura passiva a um enfrentamento de opinióes e, aos poucos, a consolidação de um grupo de trabalhadoras em atividade dispostas a concretizar um empreendimento coletivo.

Sabíamos, contudo, que o empoderamento é um processo contínuo e que requer a atualização nos diferentes espaços e momentos. Neste sentido, entre outras açóes, foram criados debates em torno da continuidade do projeto, bem como sobre as atividades que as participantes e a comunidade de modo geral queriam promover na segunda fase; passamos também a ampliar as nossas intervenções na comunidade no sentido de fortalecer a participação de outros moradores e instituiçóes (Associação de Moradores) nos processos de desenvolvimento comunitário.

\subsection{Segunda fase}

Entre a primeira e a segunda fase do projeto, houve um longo período com poucas atividades, considerando que o recurso financeiro da primeira edição do projeto já havia encerrado e aguardávamos a consolidação do segundo contrato. A ideia original era a de que as atividades não encerrariam, porém, com o atraso dos recursos e o aumento das dificuldades financeiras para manter o empreendimento coletivo, grande parte do grupo de participantes precisou procurar novas formas de sobrevivência. Era a urgência do cotidiano que as chamava.

Transcorrido alguns meses, o contrato de patrocínio foi renovado e a verba liberada para darmos continuidade as açóes. A partir daí, paulatinamente, o grupo de mulheres foi sendo reestruturado; convites abertos para a comunidade foram realizados conforme a necessidade do grupo, que almejava se consolidar com um número entre 20 a 25 participantes. Atividades relacionadas a formalização jurídica do empreendimento passaram a ser desenvolvidas sistematicamente com a participaçáo de todas as trabalhadoras.

Após quase um ano de encontros permeados de debates e reflexóes, o estatuto social da cooperativa foi finalizado. A assembleia de constituição do empreendimento, com a eleição dos cargos diretivos também foi realizada, iniciando o processo de planejamento para a oficialização das atividades e recebendo um nome: Cooperativa de Panificação e Padaria Joana d'Arc.

Paralelamente às atividades de implementação do empreendimento, um conjunto de açóes foi desenvolvido para fortalecer os recursos humanos existentes na comunidade, visando o exercício de atividades direcionadas ao público infantil. Em um primeiro momento, foram realizadas oficinas de criação de brinquedos, de teatro e de contação de histórias que, além de possibilitar o debate dos temas específicos, sensibilizaram um grupo de 19 pessoas para a formação subsequente em Educador Assistente ${ }^{2}$ (EA). Tal qualificação teve duraçáo de quatro meses e foi composta por uma parte teórica e outra prática, com estágios em escolas infantis.

Contudo, algumas das participantes/educandas, que mostraram interesse e desejo nessa formação, não tinham os requisitos mínimos no que se referia a idade e/ ou escolaridade para concluí-la nas escolas infantis. Assim, criamos junto à comunidade 
modos alternativos para a realização do estágio, inserindo as participantes em locais de educação infantil informais, como no Espaço Joaninha ${ }^{3}$ e em outras atividades das associaçóes comunitárias da região. É importante destacar que a interação entre educadores (professores do curso EA), educandas e mães possibilitou reinventar espaços de proteção e cuidado para as crianças.

Com o término do estágio, algumas das famílias que tiveram seus filhos atendidos pelas educandas nas instituições conveniadas solicitaram a realização de encontros com diferentes atores sociais (equipe do projeto, educadoras, dirigentes das escolas, etc.) para discutir a necessidade de ampliaçáo do acesso à educação infantil no município, em especial, na região em que estão inseridas. Este grupo se auto-organizou e participou de reunióes do Orçamento Participativo, levando tal demanda para debate.

Em uma perspectiva de continuidade das açóes, ou seja, da sustentabilidade das iniciativas a médio e longo prazo, nossas últimas açóes na comunidade foram a construção de uma sede para o empreendimento coletivo e para a Associaçáo de Moradores. Todo o processo foi amplamente discutido com a comunidade em reunióes e encontros informais: a construção das plantas, a contratação das empreiteiras, o pagamento dos serviços prestados, a composição dos ambientes, etc.

Até certo ponto, já esperávamos enfrentar momentos difíceis de negociação e mediação em torno desta atividade, mas o processo de planejamento e construção da obra foi um desafio muito maior do que imaginávamos. Novos problemas levaram a atrasos significativos para o término da obra, o que pela segunda vez desmotivou e desestruturou parte do grupo de mulheres que estava organizado em torno do empreendimento.

Atualmente, em termos estruturais, a cooperativa tem seu espaço físico e todo o maquinário necessário para a produção de pães, salgados e doces; Associação de Moradores tem uma sala a mais, ampla e versátil, podendo abrigar desde festas a quaisquer outras atividades formativas e/ou educativas. Já o grupo de mulheres que comporiam a cooperativa, no entanto, encontra-se novamente em fase de formação, já que algumas das trabalhadoras conseguiram se inserir no mercado de trabalho, outras mudaram de comunidade, mas há um núcleo que nunca deixou o sonho do empreendimento coletivo de lado e que segue trabalhando na perspectiva de que haja a sua efetiva consolidação.

Buscando sintetizar esse conjunto de açóes desenvolvidas, apresentamos a seguir um quadro que ilustra o desenho de nossa metodologia e intervenção na comunidade.

Para finalizar nossa descrição das fases do projeto, é importante destacar que a metodologia utilizada foi essencialmente participativa e dialógica, inspirada na educação popular desenvolvida por Paulo Freire (1987). Partimos do pressuposto de que é a partir da situação concreta do grupo, da experiência vivida e da reflexão crítica sobre ela mesma que a transformação pode ocorrer. Assim, nossa intervenção na comunidade procurou fomentar processos de diálogo, de tolerância e de compreensão do outro e da diferença, acreditando também na potencialidade do conflito como um dispositivo tensionador e constitutivo da participação e, por isso, algo para não ser negado no seio dos grupos. $\mathrm{O}$ exercício da ação dialógica, portanto, é o que fundamentou nossas açóes em busca da construção de um processo de autonomia dos sujeitos e grupos. 


\section{METODOLOGIA PARTICIPATIVA - Projeto Joana d'Arc em Luta pela Dignidade}

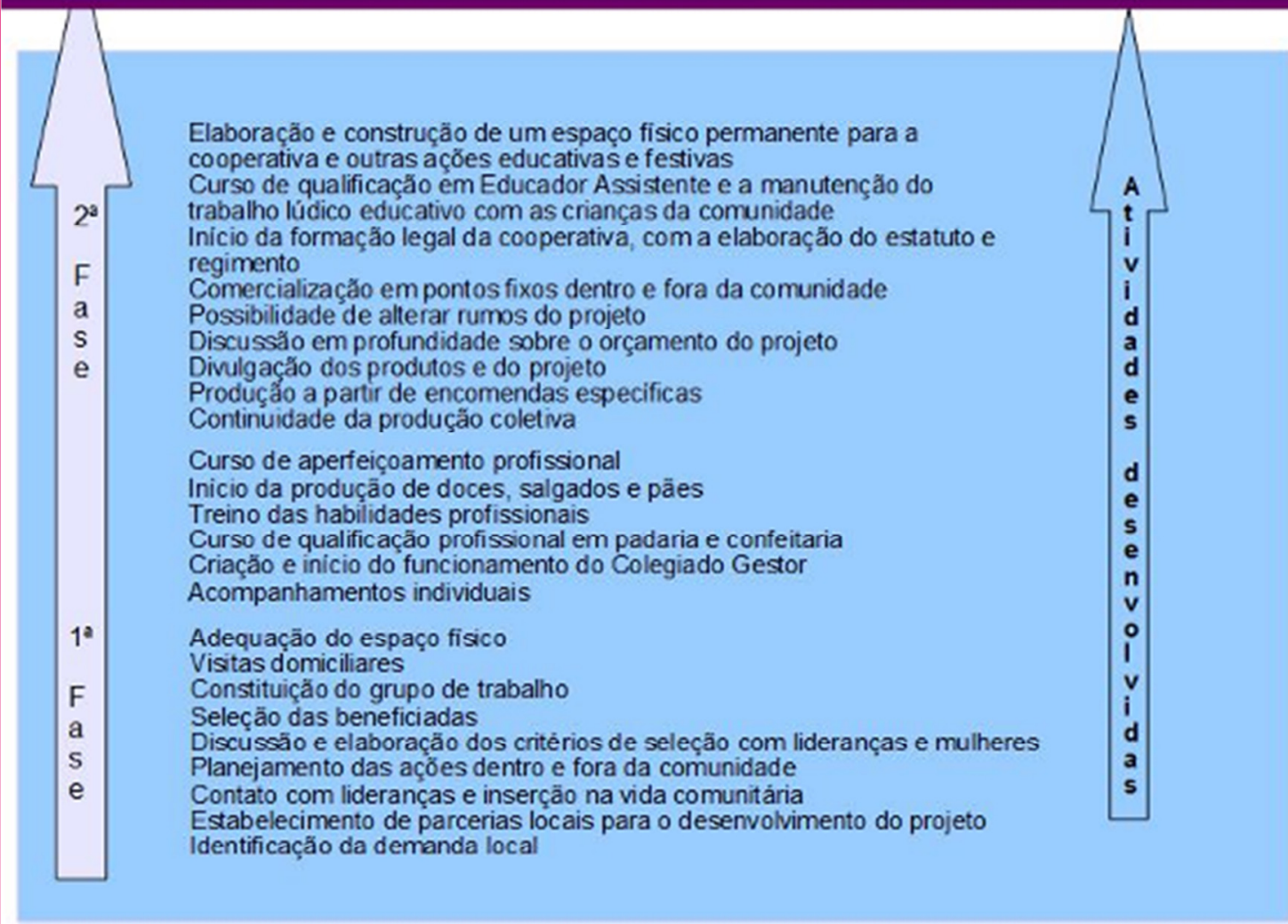

\begin{tabular}{|c|c|c|c|c|c|c|}
\hline \multirow{2}{*}{$\begin{array}{l}\text { Estratégias } \\
\text { para a } \\
\text { adesăo e } \\
\text { permanência } \\
\text { das } \\
\text { beneficiadas e } \\
\text { para o alcance } \\
\text { dos objetivos }\end{array}$} & $\begin{array}{l}\text { Fornecimento } \\
\text { de bolsas de } \\
\text { reforço } \\
\text { alimentar }\end{array}$ & \multicolumn{2}{|c|}{$\begin{array}{l}\text { Estabelecimento de } \\
\text { vinculos e relaçōes } \\
\text { horizontaise } \\
\text { significativas }\end{array}$} & $\begin{array}{l}\text { Respeito ao } \\
\text { saber e ao } \\
\text { tempo do } \\
\text { outro }\end{array}$ & \multirow[b]{2}{*}{$\begin{array}{l}\text { Reflexão } \\
\text { continua } \\
\text { sobre si e a } \\
\text { vida } \\
\text { comunitária }\end{array}$} & $\begin{array}{l}\text { Gestão } \\
\text { transparente e } \\
\text { coletiva }\end{array}$ \\
\hline & $\begin{array}{l}\text { Criaçăo } \\
\text { manuter } \\
\text { Espaço- } \\
\text { para as }\end{array}$ & & $\begin{array}{l}\text { Escuta } \\
\text { permaner } \\
\text { necessid }\end{array}$ & & & \\
\hline
\end{tabular}

Objetivo geral: contribuir de forma significativa para a melhoria na qualidade de vida dos moradores da Vila Joana d'Arc

Especifcos: 1) Construir uma cooperativa (confeitaria e panificadora) para a geração de trabalho e renda com mulheres, assegurando o trabalho coletivo e a solidariedade;

2) Promover atividades educativas/reflexivas com as mulheres beneficiadas, proporcionando 0 conhecimento e a valorização de si e da comunidade;

3) Proporcionar um espaço de convivência lúdico-educativo e extra-escolar para as crianças das familias participantes no Projeto gerando, desta forma, condiçర̄es para a participaçăo feminina na cooperativa $e$, ao mesmo tempo, o desenvolvimento das potencialidades destas crianças.

Fonte: autoria própria

\section{Reflexóes e questóes para náo finalizar}

Como imaginar um mundo diferente, onde não haja (ou haja menos) exploração de uns sob os outros? O capitalismo, em toda sua grandiosidade, aprisionou nossos pensamentos e açóes dentro de si mesmo e nos fez acreditar que não haveria uma saída de seu próprio mecanismo - prova disso é que tal sistema nunca conseguiu um nível de aceitação, desde seu primórdio, tão alto quanto nesta época atual (SANTOS, 2002). 
A proposta de promover o desenvolvimento comunitário a partir da Economia Solidária busca desnaturalizar essa construção histórica, romper com a apatia social e abrir novos caminhos para o avanço da solidariedade como um princípio ético-político. Sabemos que o conceito de desenvolvimento comunitário também pode acobertar práticas opressivas, visando a manutenção do status quo, vide as inúmeras atividades ligadas às empresas que praticam a famosa Responsabilidade Social embasadas na filantropia e caridade.

Então, se sabemos que o conceito utilizado para falar sobre determinada realidade nem sempre manifesta a prática daquele que o enuncia, como podemos analisar a força de uma ação que se propóe a fomentar a transformaçáo social? Do nosso ponto de vista, somente a observação do cotidiano poderá sinalizar a intensidade de uma experiência, isso porque o vínculo, a amorosidade e a humildade só podem ser vividos e confrontados na relaçáo com o outro. A militância sugere uma intensa implicaçáo de si com o processo, uma esperança que se vitaliza com a mudança, mas também com as dificuldades, e que é capaz de respeitar (espera ativa) o tempo para o processo de transformaçáo acontecer.

É importante aqui ressaltar a ambiguidade e a angústia decorrentes do impasse em relação à vivência do tempo. Se, por um lado, buscamos desenvolver a sensibilidade para respeitar o processo de transformaçáo social dentro do tempo necessário para emergir novas consciências, por outro, trabalhamos dentro de limites institucionais que cobram resultados precisos dentro de um período de tempo estabelecido longe da comunidade. $\mathrm{O}$ papel de educador, nesse caso, é também o de mediador com as várias instâncias que estáo coletivamente contribuindo para o desenvolvimento de determinado grupo.

Acreditamos que com tempo e com a experiência vivida, resgatada e analisada criticamente é que podemos tensionar para a mudança. Contudo, um outro grande desafio se coloca: como realizar planejamentos a médio e longo prazo, como um plano de negócios para o empreendimento, quando os sujeitos estão preocupados com o agora/ o hoje? Poderíamos levar a compreensão para o lado do imediatismo da sociedade de consumo, etc., mas não é disso que se trata. O problema da fome, por exemplo, é concreto e solicita urgência, por isso alguns esforços em termos estatais de fato têm contribuído para amenizar o problema, mas estamos longe de resolvê-lo.

Frente a isso, a nossa estratégia de intervençáo também se volta para o lado emergencial das famílias que participam do projeto, com o fornecimento de bolsas de reforço alimentar nos períodos de qualificaçáo e aprendizado profissional. Com esse apoio concreto e os acompanhamentos realizados com as trabalhadoras individualmente e em grupo, o número de desistência ao longo do curso foi mínima, contrariando, evidentemente, o discurso preconceituoso e fatalista de que as classes economicamente empobrecidas são acomodadas. Aos olhos dos desnecessitados, a nossa prática cria a dependência, mas, aos nossos, essa ação se faz humana a cada momento, uma vez que a empatia nos possibilita estabelecer um contato íntimo e verdadeiro com o outro.

Por vezes, tomamo-nos repetindo açóes sem refletir, sem considerar de onde elas partem; somos parte de um todo e o reproduzimos. A figura do oprimido e a sombra do opressor estáo introjetadas, em alguma medida, em todos nós, mas isso náo se configura em um problema quando a reflexão e o verdadeiro diálogo estấo contemplados, pois é justamente na coletividade, na relaçáo com o outro, que buscamos nos humanizar, nos libertar. 


\section{Referências}

FREIRE, P. Pedagogia do oprimido. Rio de Janeiro: Paz e Terra, 1987.

FREIRE, P.; HORTON, M. 0 caminho se faz caminhando: conversas sobre educação e mudança social. Petrópolis: Vozes, 2003.

FREIRE, P.; SHOR, I. Medo e ousadia: o cotidiano do professor. Rio de Janeiro: Paz e Terra, 1986.

GUARESCHI, P. Comunicação e Teoria Crítica. In: (coord.). Comunicação e Controle Social. Petrópolis: Vozes, 1993.

. Empoderamento. Em: REDIN, Danilo; ZITKOSKI, Jaime (orgs.) Dicionário Paulo Freire. Belo Horizonte: Autêntica Editora, 2008.

Psicologia social crítica: como prática de libertação. Porto Alegre: EDIPUCRS, 2004.

LIPOVETSKY, G. A Era do Vazio. Lisboa: Relógio d'Água, 1993.

MORETTI, C. Z. M. Militância. In: STRECK, D.; REDIN, E.; ZITKOSKI, J. (orgs.). Dicionário Paulo Freire. Belo Horizonte: Autêntica, 2008.

SANTOS, B. A crítica a razão indolente: contra o desperdício da experiência. Porto: Edições Afrontamento, 2000.

SANTOS, B. Produzir para viver: os caminhos da produção não capitalista. Rio de Janeiro: Civilização Brasileira, 2002.

SOARES, L. T. Os custos sociais do ajuste neoliberal na América Latina. São Paulo: Cortez, 2002.

Singer, P. Introdução à economia solidária. São Paulo: Fundação Perseu Abramo, 2002.

SINGER, P. Economia Solidária. In: CATTANI, A. D. (Org.). A outra economia. Porto Alegre: Veraz Editores, 2003.

ZAPATTA, T; Parente, S. 0 desenvolvimento institucional e a construção de parcerias para o desenvolvimento local. Brasília: Projeto BNDES - Desenvolvimento Local - Cooperação Técnica do PNUD, 2002. 